\title{
LA CASA DE NAZARETH \\ O LOS PRESAGIOS DE LA VIRGEN
}

Por Xavier Moyssén

A Paul Guinard, eminente zurbaranista

Un cuadro singular por su tema en la pintura española del siglo xvir, es el de La casa de Nazareth, de Francisco de Zurbarán. El cuadro es propiedad del Museo de Bellas Artes de Cleveland, Ohio, y según la autorizada opinión de María Luisa Caturla, corresponde a la producción juvenil del maestro de Fuente de Cantos; en el catálogo del Museo de Cleveland se sitúa su factura entre los años 1638-40, sin embargo, Paul Guinard lo fecha hacia 1630, año aceptado por otros historiadores (figura 1). La pintura fue dada a conocer en 1960 por el citado museo, en ese año se reprodujo en color por primera vez, en el imprescindible estudio de Paul Guinard sobre el artista barroco. ${ }^{1}$

El tema de La casa de Nazareth en la forma como Zurbarán lo interpretó en este cuadro, no fue común en la pintura española anterior y posterior a él; sí, en cambio, un tema semejante como el de El taller de Nazareth, se dio con frecuencia en la obra de diversos maestros en distintas épocas. ${ }^{2}$ Quizá con mayor propiedad el cuadro debía titularse Los presagios de la Virgen, pues eso es lo que acontece a ella en esa escena íntima dentro del hogar de Nazareth: presiente ya, a través del accidente que ha sufrido el Niño, cuál habrá de ser el fin de su misión una vez que se le haya coronado con las zarzas espinosas.

La originalidad de la composición zurbaranesca en esta obra, ha dado lugar a diversos estudios, si bien en ninguno de ellos se ha llegado a una conclusión satisfactoria; máxime que se desconoce con detalle el pedigree del cuadro. En España existen dos o tres telas semejantes a la de Cleveland, más ninguna se adjudica a Zurbarán con seguridad. Una de ellas se exhibió en 1953 en Granada, en la primera gran exposición que al artista se le dedicó. Como de esos cuadros no conozco

1 Zurbaran et les peintres espagnols de la vie monastique. Les editions du temps. Paris, 1960.

2 Consúltese: F. J. Sánchez Cantón: Nacimiento e infancia de Cristo, pp. 167-74. Biblioteca de Autores Cristianos. Madrid, 1948. 
reproducción alguna, me abstengo de formular cualquier comentario en relación tanto con el cuadro de Cleveland, como de los que existen en México con el mismo asunto.

Es ya de dominio común entre los estudiosos de la pintura española, la falta de originalidad que acusa en algunas obras Francisco de Zurbarán, si bien tal limitación no fue exclusiva de él; otros afamados maestros y entre ellos se encuentra el propio Velázquez, acudieron a los recursos de los grabados para la composición de sus obras; grabados de procedencia flamenca en la mayor parte, ya que también los hubo alemanes, italianos y franceses. ${ }^{3}$ Desde mi punto de vista queda en entredicho la originalidad de Zurbarán en el asunto de La casa de Nazareth, o Los presagios de la Virgen. Debe existir alguna lámina hoy desconocida con tal tema y de procedencia flamenca. En favor de esto cuento, entre otras razones, con dos que me parecen fundamentales. La primera de ellas es el juicio de la señora Caturla quien escribió al respecto lo que sigue: "Hay además algo en esta Santa Casa de Nazareth que trae a la memoria tablas flamencas del tema de la Anunciación." " La segunda razón se encuentra en el cuadro mismo: tanto la amplia falda de la Virgen como la túnica que viste el Niño, no obstante la aparente sencillez que tienen en sus acartonados dobleces, en el fondo se adivina la compleja labor de los rígidos quiebres que son comunes en las pinturas y grabados flamencos anteriores al Renacimiento. Al ocuparme de los cuadros de México, volveré a insistir en la posible existencia de una estampa de la que salió la composición de Zurbarán.

3 El primero en advertir el empleo de grabados en la obra de Francisco de Zurbarán fue Diego Angulo Jñiguez; en 1931 en su artículo "Miscelánea de pintura seiscentista", publicó la estampa de Cornelio Cort sobre el Entierro de Santa Catalina, composición que aprovechó integramente Zurbarán para su pintura del mismo tema, de la colección sevillana del Conde de Ibarra. Vide Archivo Español del Arte y Ar: queologia, pp. 63-71, Vol. VII, No 19. Es interesante la lista de otros grabadores de los cuales dependió en mayor o menor grado, el artista extremeño: Abraham Bloemaert, Schelte de Bolswert, Hans Sebald Beham, Pedro Pablo Rubens, J. de Gheyn, Alberto Durero, Antonio Tempesta, Phillips Galle, Theodor Galle, Van Heemskerk. Hasta una influencia de Leonardo $\mathrm{Da}$ Vinci se ha querido ver en Zurbarán; su Hércules y la túnica de Neso, del Museo del Prado, se hace depender del San Jerónimo, de Leonardo, del Museo Vaticano, a través de una estampa desconocida. Ver. Alfonso Emilio Pérez Sánchez "Torpeza y humildad de Zurbarán", en Goya, número 61-63. pp. 266-275. Madrid, 1965.

4 María Luisa Caturla. "Vida y evolución artística de Zurbarán." Catálogo de la Exposición Zurbarán en el III centenario de su muerte. p. 20. Madrid, 1964. 
Sin embargo, el cuadro bien pudo tener su origen en dos fuentes diferentes, recuérdese que en 1630 el maestro fechó el Niño de la espina de la colección Manuel Sánchez Ramos, de Sevilla; en esta obra el tema es rotundo, independiente (figura 11). Existen otras telas con idéntico asunto, si bien la composición del ambiente cambia como en los cuadros de las colecciones del Duque de Sotomayor, de Madrid y Los Ángeles, Country Museum. 5 Si Zurbarán utilizó dos grabados para la composición de La casa de Nazareth, uno de ellos debía representar al Niño de la espina. De ser acertada tal suposición así vendría a explicarse la falta de unidad que se advierte en la composición del cuadro; pues tanto la figura del Niño como la de la Virgen, parecen desligadas entre sí, están colocadas en ámbitos distintos, se diría que hay entre ellas espacios y planos diferentes, no concordantes. Respecto a la figura de la Virgen, José Manuel Pita Andrade recordando lo que el maestro de Fuente de Cantos debe a los grabadores, vio con especial intuición en la lámina de Alberto Durero Melancolia I, el posible origen de la figura meditativa de la Virgen. ${ }^{\circ}$

La influencia de Francisco de Zurbarán en la pintura barroca de la Nueva España, fue decisiva y prolongada en el tiempo; hacia la cuarta década del siglo xviı se inicia su presencia la que habrá de extenderse, por lo menos, hasta la primera década del siglo siguiente. Tal influencia penetra en dos formas; a la primera corresponde la llegada a estas tierras de cuadros debidos a su propia mano, o salidos de su taller; la segunda se relaciona con el arribo de algunos artistas andaluces que han trabajado al lado del maestro o, por lo menos, están al tanto de su estilo. También están informados de la demanda de obras que tiene, gracias a su personal manera de pintar con la que satisface tanto el gusto como la devoción de fieles y donantes. El número de zurbaranistas que hay en la pintura de la Nueva España es considerable. Mas no es esta la ocasión de hablar de la influencia de Zurbarán en la pintura virreinal novoespañola; para ello existen varios estudios a los cuales debe recurrìr el interesado. ${ }^{7}$

5 Emilio Gómez Piñol. "Una obra inédita de Zurbarán: El Niño de la Espina, de Oñate". Archivo Español de Arte, núm. 153, pp. 9-23. Madrid, 1966.

6 "El arte de Zurbarán en sus inspiraciones y fondos arquitectónicos". Goya, núms. 61-63, pp: 242-48. Madrid, 1965 .

7 Antonio Bonet Correa. "Obras zurbaranescas en México." Archivo Español de Arte. Núms. -146-47, pp. 159-168. Madrid, 1964. Gonzalo Obregón. Zurbarán en México. Badajoz, 1964. Xavier Moyssén "Zurbarán en la Nueva España". Conciencia y autenticidad históricas, pp. 221-235. México, 1968. 
En el libro Conciencia y autenticidad históricas publicado en 1968 como homenaje académico al doctor Edmundo O'Gorman, dí a conocer la existencia en México de un interesante cuadro con el tema zurbaranesco de La casa de Nazareth. (Figura 2). Esta pintura de mediana calidad, salvo en el rompimiento de gloria que tiene en la parte superior central, es idéntica a la tela del Museo de Cleveland. Su presencia me planteó problemas: ¿se trataba de una copia directa, aunque alterada, del cuadro de Zurbarán?, cera o no, una obra salida del taller del maestro?, ¿el cuadro se habia pintado en la Nueva España siguiendo la pauta de un ejemplar del grabado que bien pudo haber manejado el propio Zurbarán? La aparición en una iglesia pueblerina de una tela con el tema de El taller de Nazareth, básicamente compuesta conforme al patrón del cuadro de Cleveland (figura 5), me llevó al convencimiento de que la pintura se había realizado en México mediante el modelo de una estampa que también habia circulado en la península; esto último lo pude confirmar con las siguientes palabras de María Luisa Caturla escritas a propósito de la tan citada pintura de Cleveland: "en España han quedado varias repeticiones o copias antiguas, una de ellas que entonces era la mejor versión de las existentes, estuvo expuesta en Granada en 1953". 8 La existencia de otros cuadros localizados posteriormente, me llevaron a una doble conclusión: el tema de La casa de Nazareth fue interpretado libremente por los artistas novoespañoles, utilizando para ello un grabado que hasta la fecha nos es desconocido, la misma fuente fue empleada por Francisco de Zurbarán y su originalidad en el cuadro de Cleveland queda en entredicho.

Las distintas versiones que hay en México de La casa de Nazareth. dependen básicamente del núcleo central que hay en la composición del cuadro del Cleveland Museum. Aparte de las figuras del Niño y la Virgen, no faltan la mesa con el cajón entreabierto, ${ }^{9}$ los libros y las peras que están sobre la cubierta, el jarrón con las simbólicas azucenas, las palomas, el cesto con la costura, las columnas y el pesado cortinaje del fondo; todo está dispuesto en el mismo orden. Las mo-

8 En la obra citada en la nota 4.

9 No deja de ser curioso el hecho de que Zurbarán se repitiera al pintar la misma mesa, con el cajón entreabierto ‘como simbolo de lo que habrá de venirr, en los siguientes cuadros: Curación milagrosa del beato Reginaldo de Orleans, iglesia de Santa Magdalena, Sevilla; La Virgen Niña, en la Colegiata de Jeréz; La Virgen Niña en oración, del Museo Metropolitano de New York; El Niño de la espina, de la colec. ción Sánchez Ramos de Sevilla. 
dificaciones o novedades que los cuadros tienen serán vistas a continuación. ${ }^{10}$

Aun cuando ya he publicado la pintura que muestra la figura 2, propiedad de un coleccionista de la ciudad de México, ${ }^{11}$ me ocupo de ella nuevamente para seguir aquí las modificaciones que en su composición sufrió el tema del cuadro de Zurbarán, en una serie de obras debidas a pintores activos en los siglos xvir y xvir en la Nueva España; ellos, como el maestro peninsular, tuvieron en sus manos el mismo grabado, pero cada uno introdujo variaciones bien por gusto propio o por exigencia devota de quienes encargaron las obras.

Dejando a un lado la calidad artística y el estado de conservación que guarda el cuadro, éste muestra como novedad una animada escena en la parte superior central, donde un grupo de robustos y rubicundos ángeles portan la cruz. El grupo angélico proviene de otra fuente impresa. Con la introducción de los ángeles portadores de la cruz, el tema del cuadro deja de ser La casa de Nazareth, para convertirse con mayor propiedad en las Premoniciones o Presagios de la Virgen; lo que ella presiente al ver el dedo herido del Niño, está ya presente en el grupo de angelillos, ellos llevan la cruz en la que habrá de ser sacrificado. El empleo de un grabado antiguo de origen flamenco, en el cual he insistido, parece quedar demostrado en el problema que tuvo que afrontar el anónimo pintor de este cuadro, al ocuparse tanto del traje de la Virgen como de la túnica del Niño; los complicados dobleces que tienen, tan torpemente resueltos, provienen de la interpretación que se dio a los quebrados diseños lineales que son propios de los ropajes que aparecen en los grabados flamencos del siglo xv. Esta tela aparte de su mal estado de conservación fue mutilada bárbaramente en el sitio en que debió estar colocado el cesto con las labores de costura de la Virgen; si ese fragmento existe y si su factura es óptima, hoy día puede considerarse como un cuadro independiente, como una naturaleza muerta.

En la sacristía de la Basílica de Guadalupe se conserva otra de las versiones de La casa de Nazareth, existentes en México. (Figura 3). El cuadro mide $1.17 \times 1.88 \mathrm{mts}$, está firmado en la parte inferior derecha por José Rodríguez Carnero, pintor que trabajó activamente

10 Un estudio detenido del cuadro y de los símbolos que hay en él fue hecho por Henry S. Francis: "The Holy of House of Nazaret." The Bulletin of the Cleveland Museum of Art. XLvis, 1961.

11 Vide: "Zurbarán en la Nueva España", Conciencia y autenticidad históricas, pp. 231-33, figs. 9 a 12 . 
en Puebla entre los siglos xvir y xvir, falleció en 1725. Rodríguez Carnero es uno de los más notables zurbaranistas de la pintura barroca poblana, su extensa obra, siempre interesante, está en la espera inútil de ser estudiada. 12

De gran interés son las modificaciones que hizo José Rodríguez Carnero en su versión de La casa de Nazareth. Por principio de cuentas suprimió todo rompimiento de gloria o de luz celestial, en cambio introdujo como novedad la imagen de San José; un San José, por cierto, que parece indiferente a la escena que se desarrolla en el interior de su hogar, está como abstrafdo, con la mirada perdida en no se sabe qué lejanía. La composición fue alterada para encajar a San José atrás del Niño; su figura sobrepuesta descansa sobre un mueble. No por insignificante deja de tener interés el detalle del piso. Rodriguez Carnero lo pintó con las baldosas de barro cocido que son comunes en el pafs. Pero el motivo de mayor interés que encuentro en este cuadro, se refiere a la herida que ha sufrido el Niño; ya no se trata de unas gotas de sangre que manan del dedo lastimado, sino de un chorro que brota copiosamente (figura 4). En este detalle Rodriguez Carnero estuvo a la altura de los imagineros barrocos de la Pasión. Recuérdese aquí ese discutido gusto por "bañar" en sangre las esculturas de Jesucristo, a las que fueron tan adictos con una devoción entre morbosa y nauseabunda los feligreses virreinales.

En la iglesia de San Miguelito, en Cholula, Puebla, en el sotocoro se localiza otra interesante pintura con el asunto que ocupa nuestra atención. Por los cambios introducidos por el anónimo pintor, el téma se transforma en El taller de Nazareth (figura 5). El cuadro está ejecutado con una amplia libertad respecto a la fuente inicial; sin embargo, la Virgen y el Niño no han modificado sus posturas, permanecen en sus sitios. La mesa en cambio, ha desaparecido para dar lugar a un enorme banco de carpintero, tras el cual se encuentra San José, vestido a la usanza del siglo xviri; está ocupado labrando unos maderos. Un muro sobre el que cuelgan las herramientas del taller, limita el espacio de la habitación y una cortina descorrida deja al descubierto el paisaje idílico de un jardín. Pese a la libertad formal y a las novedades introducidas, tanto la imagen de Jesús como la de

12 Francisco Pérez Salazar, Historia de la pintura en Puebla. Edición y prólogo de Elisa Vargas Lugo. pp. 71-78. Estudios y Fuentes del Arte en México, xm. I. de I. E. México, 1963. 
DOI: http://dx.doi.org/10.22201/iie.18703062e.1975.44.1014

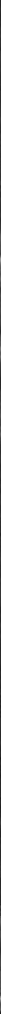

1. Francisco de Zurbarán. La casa de Nazareth. Cleveland, Museum of Fine Arts. 
DOI: http://dx.doi.org/10.22201/iie.18703062e.1975.44.1014

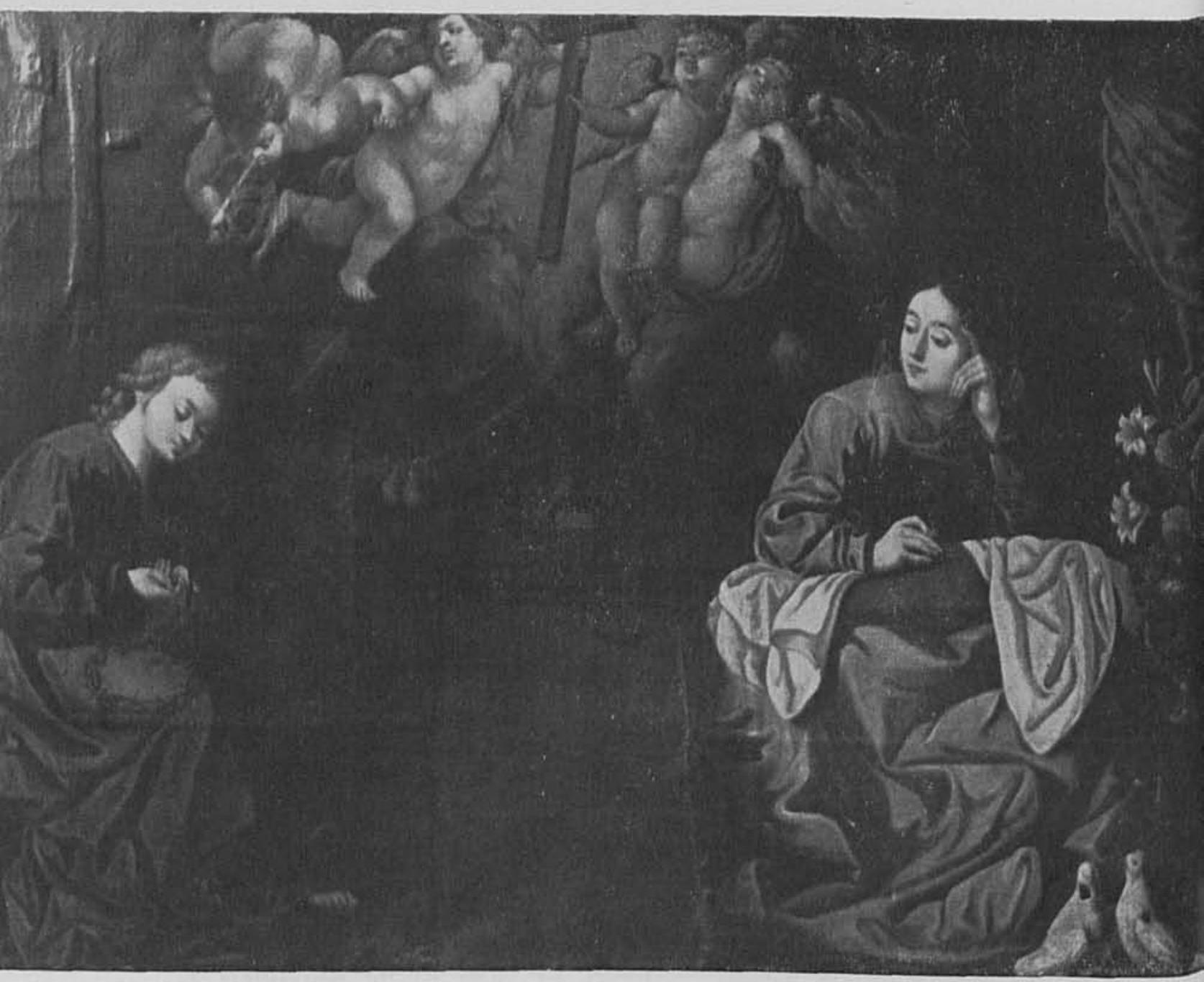

2. Anónimo. La casa de Nazareth. Colección particular. México, D. F. Foto Jesús Espinosa H. 
DOI: http://dx.doi.org/10.22201/iie.18703062e.1975.44.1014

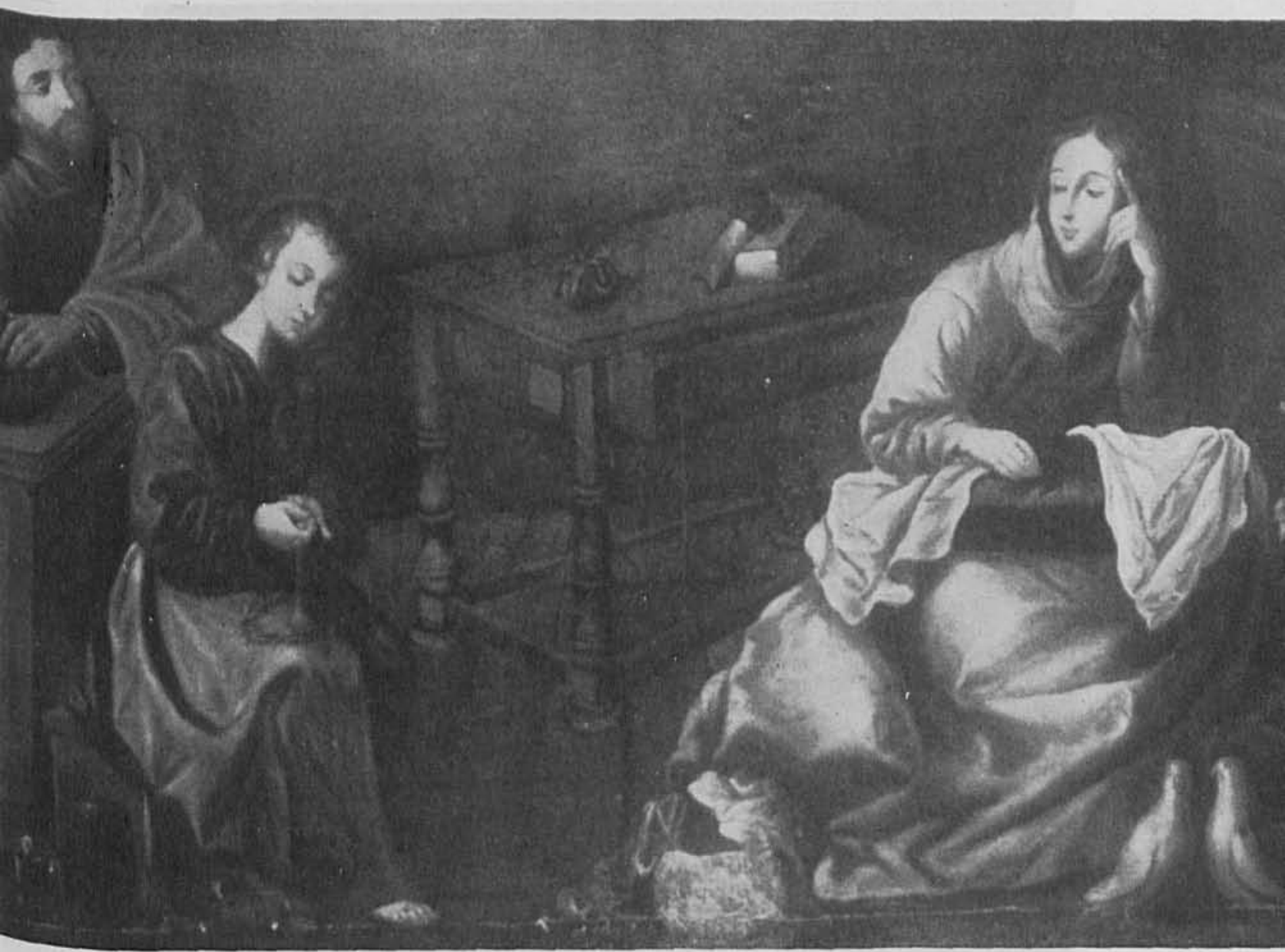

3. José Rodriguez Carnero. La casa de Nazareth. Basílica de Guadalupe. Sacristía. México, D. F. Foto Judith Puente. 
DOI: http://dx.doi.org/10.22201/iie.18703062e.1975.44.1014

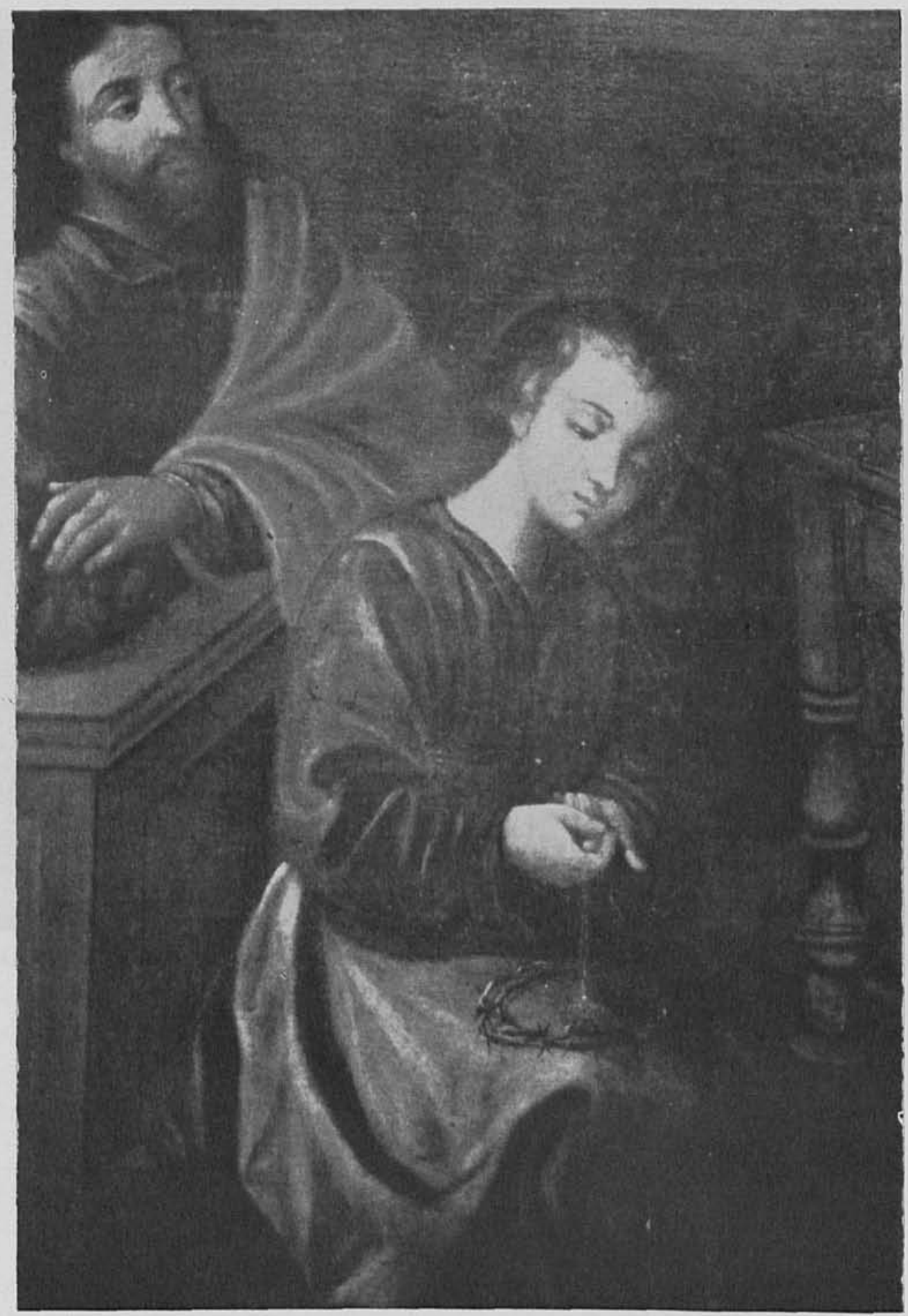

4. José Rodriguez Carnero. La casa de Nazareth. Detalle. 
DOI: http://dx.doi.org/10.22201/iie.18703062e.1975.44.1014

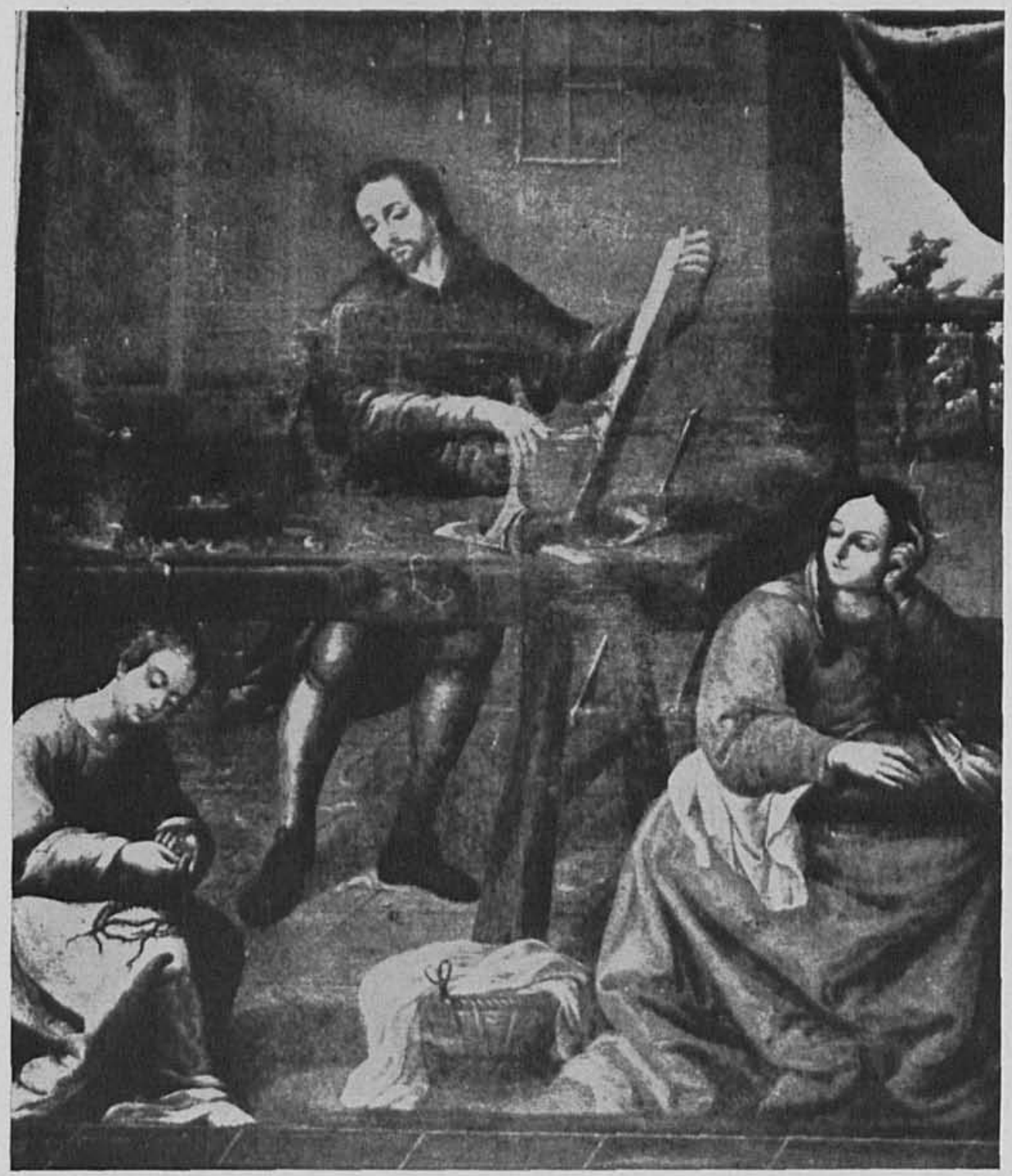

5. Anónimo. El taller de Nazareth. Iglesia de San Miguelito. Sotocoro. Cholula, Puebla. Foto Antonio Bonet Correa. 


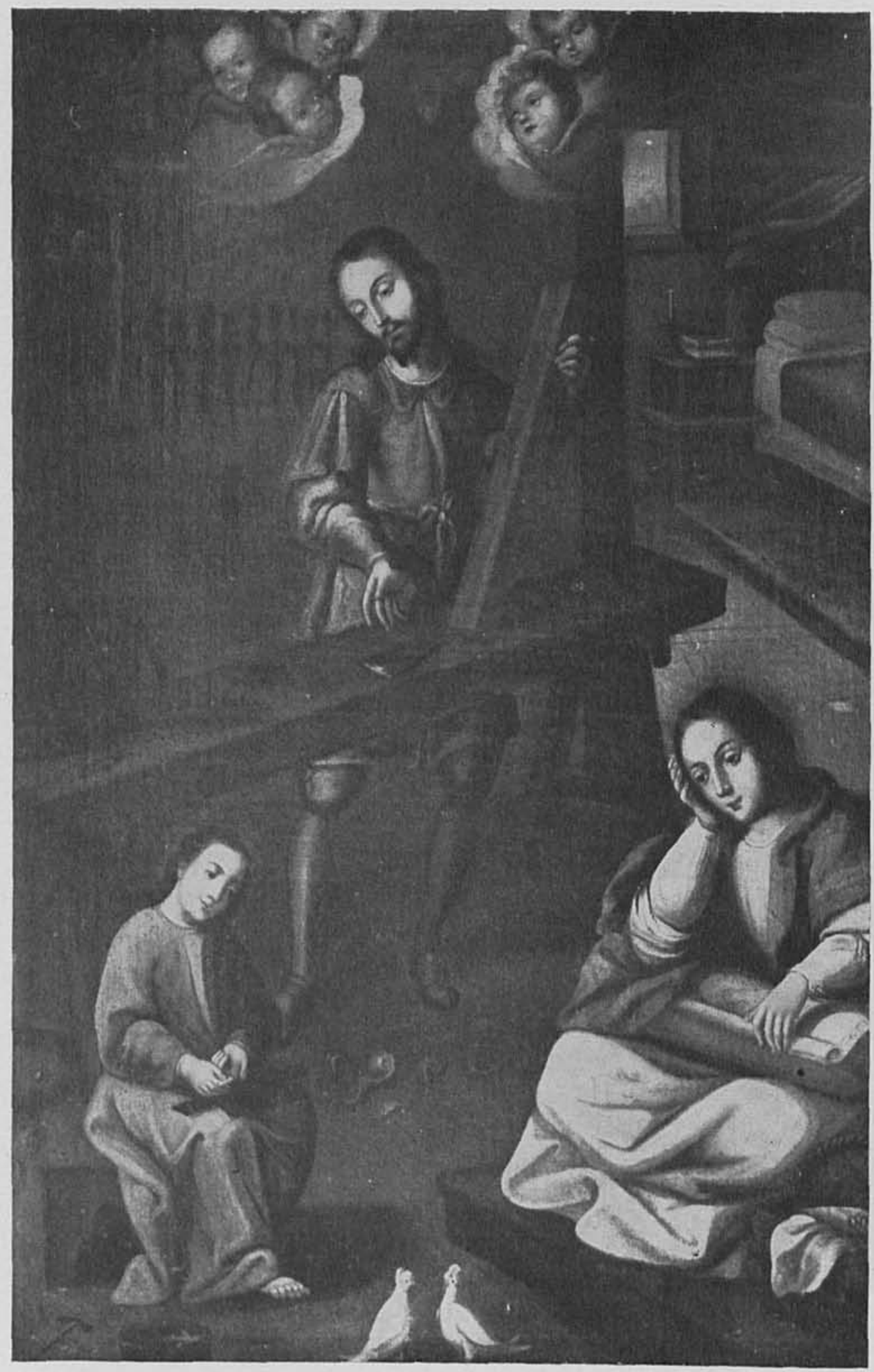

6. Anónimo. El taller de Nazareth, Col. Alejandro von Wuttenau. México, D. F. Foto Judith Hancock. 


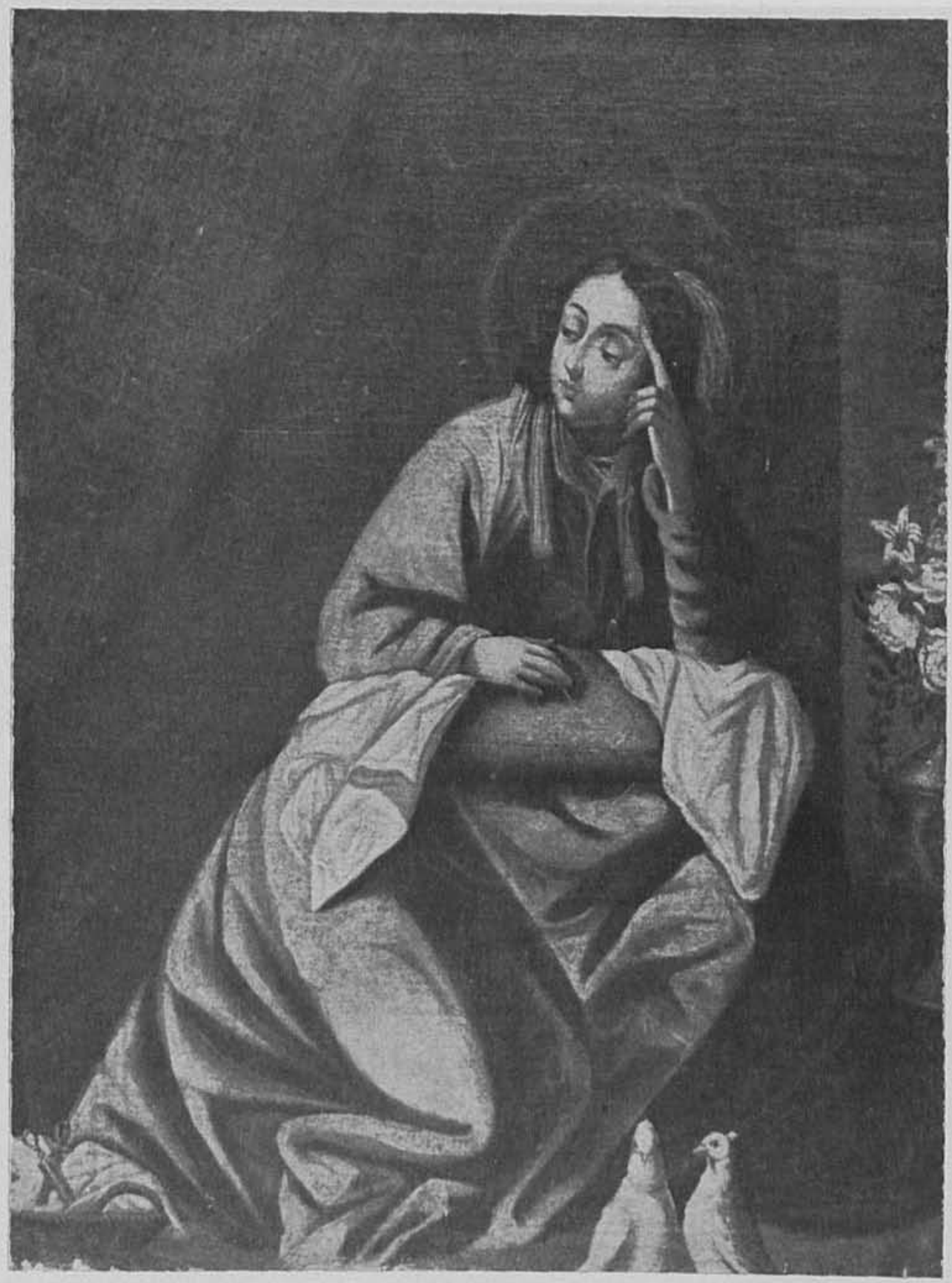

8. Anónimo. Meditaciones de la Virgen. Colección particular. México, D. F. Foto Judith Puente. 


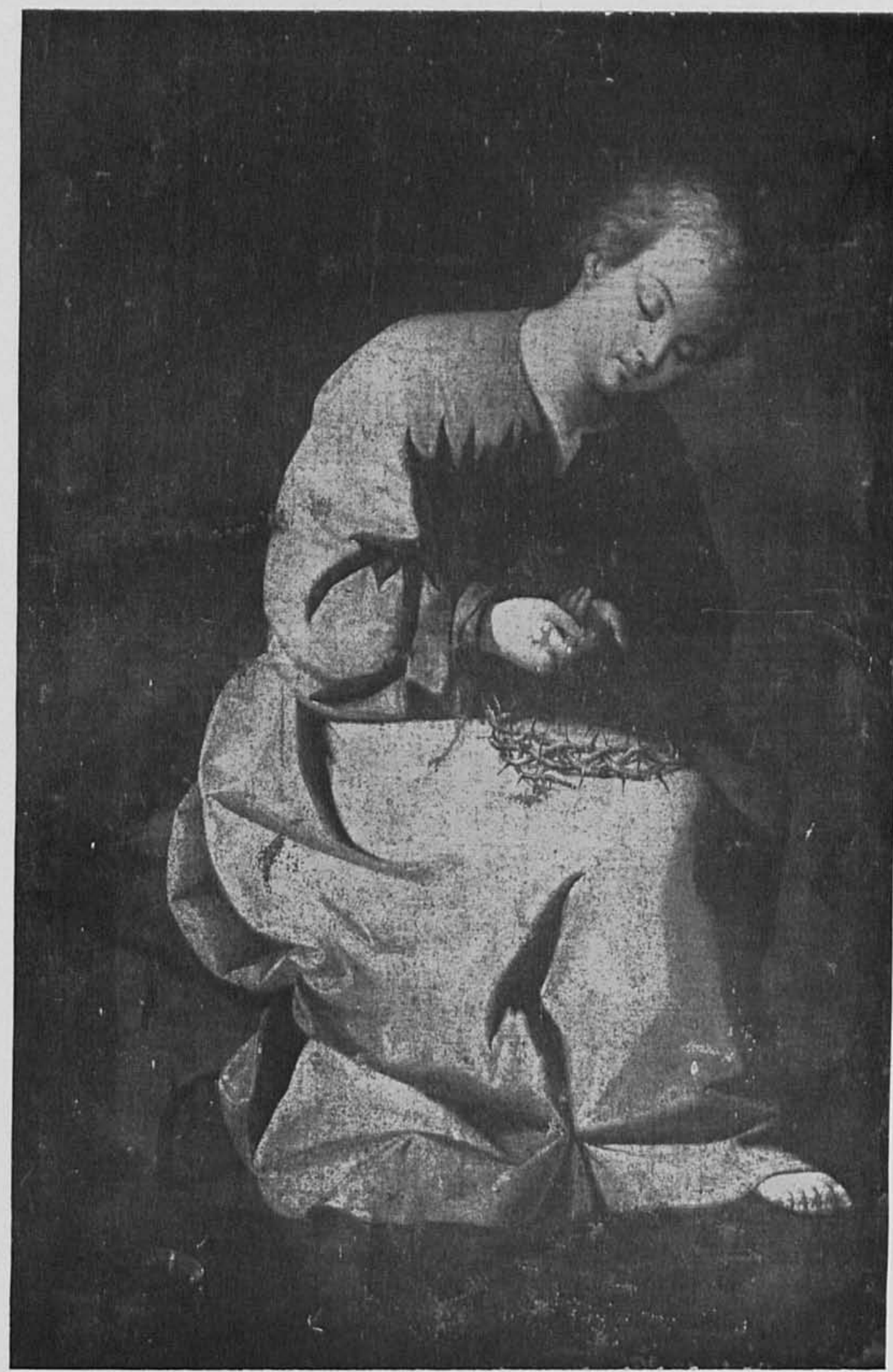

9. Anónimo. El niño de la espina. Colección Alejandro von Wuttenau. México, D. F. Foto Judith Hancock. 
DOI: http://dx.doi.org/10.22201/iie.18703062e.1975.44.1014

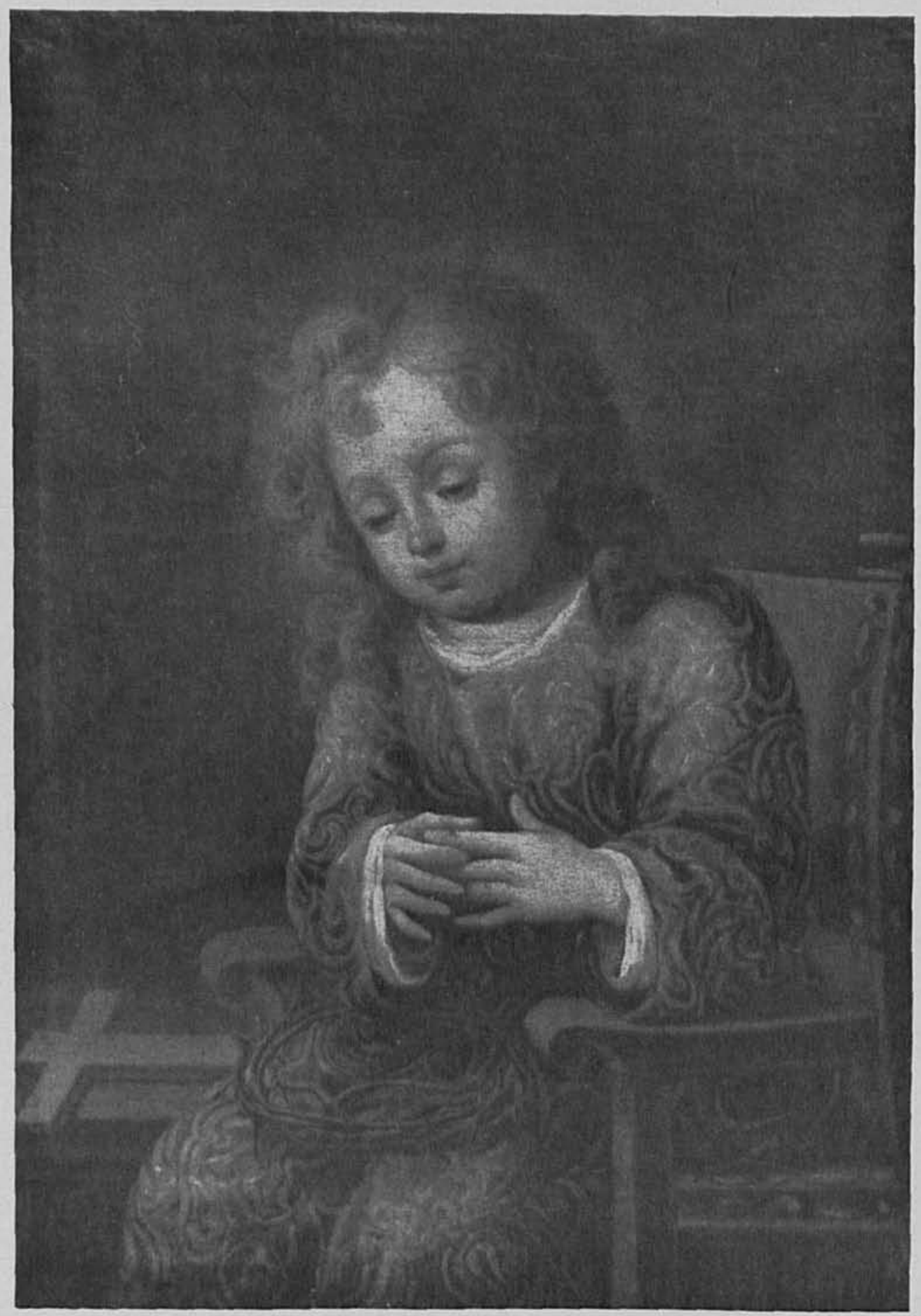

10. Anónimo. El niño de la espina. Colección particular. México, D. F. Foto Judith Puente. 


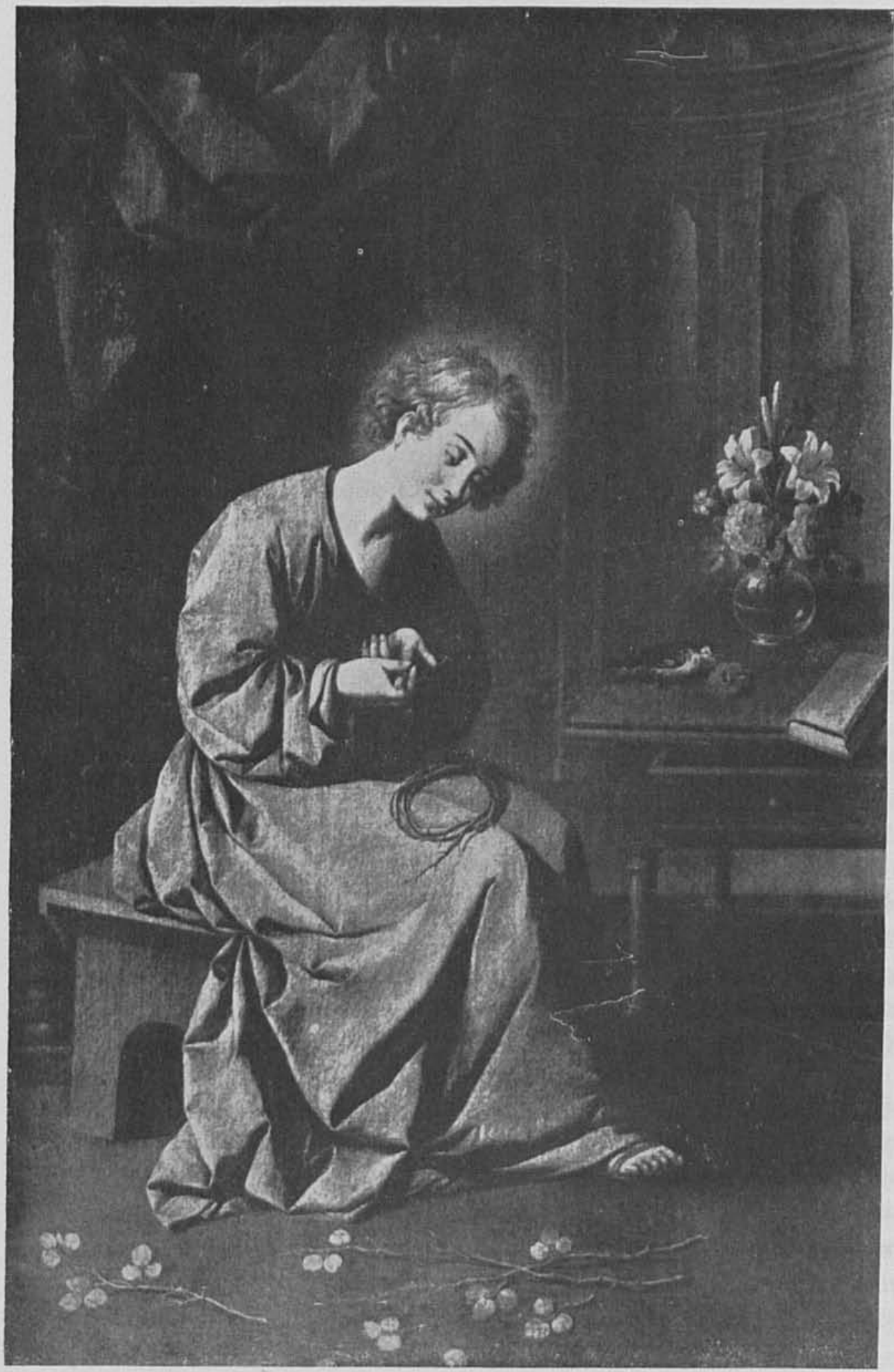

11. Francisco de Zurbarán. El niño de la espina. Colección M. Sánchez Ramos. Sevilla. Foto Amada Martínez. 
DOI: http://dx.doi.org/10.22201/iie.18703062e.1975.44.1014 
María, guardan la prestancia con la que aparecen en las otras versiones, lo cual no sucederá con la siguiente obra.

La colección de pinturas del arquitecto Alejandro von Wuttenau, cuenta con una tela sobre El taller de Nazareth (figura 6). Por su factura y expresión la pintura es de carácter popular; mide $1.37 \times 0.92$ mts. En la parte inferior del cuadro aparecen en la forma habitual tanto el Niño como la Virgen, ipero que lejos están sus figuras de las que hemos visto en los cuadros anteriores! Todo ha cambiado ihasta la colocación de las palomas! La Virgen aparece sentada sobre un estrado y ha modificado la disposición de su cuerpo; su cabeza ahora descansa sobre el brazo derecho, mientras observa entre apesadumbrada y absorta al Niño Jesús, quien se ha herido en un dedo, mas no con la espina de la corona, sino con un clavo de la cruz que El mismo fabrica, el martillo ha caído a su lado. He aquí la novedad sustancial introducida en esta curiosa y anónima pintura, los símbolos se han cambiado, en lugar de la corona de espinas encontramos la cruz, mas con una u otra, el Niño se ha pinchado un dedo. La composición del cuadro está mal resuelta, el tema del Niño y la Virgen está situado en un plano inferior en relación a la imagen de San José y todo cuanto le radea ambientalmente. El compañero de María ha interrumpido su trabajo debido al accidente, en su rostro aparece esa expresión entre anodina y dulce que es propia de toda la mediocre pintura de la segunda mitad del siglo xvir; lo mismo puede repetirse respecto a la faz de la Virgen. Como en el cuadro anterior un muro indica el límite espacial del taller; una puerta permite ver el interior de otra habitación, se trata de una alcoba, de una estancia intima donde las cortinas del dosel dejan al descubierto una alta y mullida cama; sobre el buró están colocados unos libros y una vela; una ventana entreabierta deja pasar la luz del día. Esta parte de la composición cuánto hace recordar nuevamente, ciertos grabados de procedencia flamenca que circularon en las colonias americanas a partir del siglo xvir.

Sobre la inclusión de San José en estas dos composiciones la razón debe encontrarse en la devoción que se establece hacia el compañero de la Virgen, en el siglo xviri; a partir de él las representaciones del santo son frecuentes tanto en la pintura como en la escultura; se pintan monótonas series sobre su vida, se le dedican complicados y fastuosos retablos en los que se historia plásticamente su existencia, como sucede, entre muchos ejemplos, en la iglesia de los agustinos de Salamanca, en Guanajuato. 
Retornando al tema zurbaranesco de La Casa de Nazareth, me ocuparé a continuación de dos telas, de distinta calidad y factura, las cuales debieron formar parte de una composición mayor.

El primer cuadro, (Figura 7), pertenece a la colección del señor César Rubello de la ciudad de México, mide $1.57 \times 1.30 \mathrm{mts}$. La fotografía que aquil se publica fue tomada por Martín Soria, el gran conocedor norteamericano de la pintura española y de la de Zurbarán en particular. Soria escribió de su puño y letra, en el reverso, "attributed Zurbaran", todo comentario huelga, pues si bien la anotación no indica afirmativamente que sea una obra original, tampoco lo niega, en todo caso acepta la atribución. Sin embargo, algo hay que agregar. El cuadro es la mitad de una tela mayor, según el señor Rubello el corte fue ocasionado por su anterior propietario, al dividir sus bienes para repartirlos entre sus herederos; Rubello conoció la mitad faltante con la figura del Niño, desgraciadamente no ha sido posible localizar en poder de quién se encuentra el resto de la composición. Cierta o no, la causa bárbara de la división del cuadro, es indudable que la figura de la Virgen corresponde a la composición del cuadro de Cleveland; cuesta trabajo aceptar que se trate de un cuadro aislado, autónomo en cuanto al asunto; en la sección faltante debió estar la imagen del Niño en la postura conocida. Por fortuna el estado de conservación de esta tela es magnífico.

La otra pintura a la que me he referido es propiedad de un coleccionista de la ciudad de México. (Figura 8). Es una obra muy inferior tanto por su calidad como por el estado que guarda; mide $1.08 \times 0.89$ mts. A semejanza del cuadro anterior, se trata únicamente de un fragmento de una obra mayor con el tema de La casa de Nazareth.

Al principio de este trabajo anoté que tal vez Francisco de Zurbarán había utilizado dos grabados para pintar La casa de Nazareth, en caso de no existir uno con la composición completa; también anoté que uno de esos grabados podía referirse únicamente a la figura del Niño de la espina, máxime que el maestro habia fechado en 1630 un cuadro con traza semejante. En vista del número considerable de obras existentes con el tema del Niño de la espina, sigo pensando en la existencia de una lámina que alcanzó gran circulación tanto en los talleres españoles como en los mexicanos. Lo cual, por otra parte, no impide el descontar la posibilidad de que este tema haya tenido origen en el grabado de donde salió La casa de Nazareth. 
Un cuadro con el Niño de la espina, pertenece al arquitecto Alejandro von Wuttenau, (figura 9), mide $0.83 \times 0.61 \mathrm{mts}$, aun cuando su estado de conservación no es muy satisfactorio, permite apreciar que se trata de una pintura de buena calidad. El Niño emerge de una suave penumbra gris en la que destacan los colores de la madera del banco y la vasija de cerámica. En armonía con el contexto cromático, está el color gris violáceo de la túnica que sobresale gracias a la iluminación. Un cuidadoso tratamiento se dio al colorido del rostro, manos y pies, así como a la rubia cabellera de Jesús. En las versiones conocidas del Niño de la espina, éste aparece básicamente en la misma postura, ya se sabe que no hay copia o reproducción que sea idéntica al original; lo que varfa en algunas de las versiones es el ambiente que rodea al Niño. En el cuadro de Sevilla, colección Sánchez Ramos, el Hijo de Dios se encuentra en el interior de una suntuosa estancia, a la manera zurbaranesca hay flores en el piso; en la cubierta de la mesa se halla un pajarillo picando una flor, un libro y un ánfora de vidrio con un búcaro de azucenas (figura 11). Tanto en el cuadro del Museo del Condado de Los Angeles, como en el de la colección del Duque de Sotomayor, de Madrid, el Niño se encuentra sentado a pleno aire, un paisaje convencional y distinto en las dos obras, imprime un ambiente bucólico a la composición. Por contraste en la versión mexicana, la nota distintiva es la sobriedad que tiene.

Para concluir esta investigación sobre Francisco de Zurbarán, motivada por La casa de Nazareth o Los presagios de la Virgen, deseo dar noticia de la última consecuencia a la que llegó su tema del Niño de la espina. Una tela relacionada con este asunto se encuentra en una colección particular de la ciudad de México, mide $0.68 \times 0.89 \mathrm{mts}$. (Figura 10). El Niño Jesús aparece sentado en un sillón infantil, se ha pinchado un dedo con una de las espinas de la corona que está sobre sus piernas, a su lado se haya recostada la cruz. El Niño viste rica indumentaria, una túnica de brocados; una abundante y ensortijada cabellera rubia le cae sobre los hombros. La composición de este cuadro nada tiene ya que ver con Zurbarán, por más que así lo haya clasificado su anterior poseedor, sólo resulta una mediocre y cursi interpretación de uno de los bellos temas de que se ocupó el maestro de Fuente de Cantos. ${ }^{13}$

18 Un cuadrito semejante a éste, atribuido a Juan de Valdés Leal, fue publicado en el catálogo de la Segunda Exposición de Pintura Andaluza del siglo XVII. Colecciones barcelonesas, IV. Edimar. Barcelona, 1957, lámina XXII. 
El tema de una pintura de Zurbarán que hemos tratado en esta investigación, obliga a aceptar la buena acogida que tuvo tanto en España como en México. A los fieles les debe haber movido, aparte de la devoción, el carácter sentimental y familiar que hay en la escena. Otros cuadros con este asunto aparecerán con el tiempo y el tema por el número de sus representaciones pasará a ocupar un sitio semejante al que tienen otros, como sucede en las series de apostolados, de la Virgen o San Francisco. ${ }^{14}$

14 Deseo mostrar aqui mi agradecimeinto al profesor Gonzalo Obregón, por su valiosa ayuda en esta investigación. 